\title{
O BAIRRO CIDADE MINEIRA VELHA E A CONSTRUÇÃO DA ESCOLA MUNICIPAL PADRE CARLOS WECKI
}

\author{
MINEIRA VELHA DISTRICT AND THE CONSTRUCTION OF PADRE \\ CARLOS WECKI SCHOOL
}

\section{Ana Paula Zeferino Dal molin ${ }^{1}$ \\ Giani Rabelo ${ }^{2}$}

\begin{abstract}
RESUMO: Este artigo tem como objetivo compreender os motivos que levaram a Escola Municipal Padre Carlos Wecki a homenagear um Padre como patrono, mesmo se tratando de uma escola pública, portanto laica. O estudo tem como objetivos específicos: discutir a importância da preservação do patrimônio educativo para a comunidade escolar, compreender a criação do Bairro Cidade Mineira Velha no qual está situada a escola e, ainda, traçar uma breve história da escola. A pesquisa foi do tipo documental e teve como fontes o Projeto Político Pedagógico (PPP) da escola, o livro "Cidade dos Mineiros" de Dirlene Brunelli, Clemente Borges e Luiz Lima, bem como outros documentos escolares. Esta escola, assim como boa parte das instituições, está tomadas pela cultura do descarte, pois muitos documentos já não existem mais, dificultando a reconstrução da sua trajetória e sobre o que motivou a escolha do patrono. Ainda, a prática de colocar um religioso como patrono evidencia o quanto o estado brasileiro não é laico na sua plenitude, como prescreve a Constituição da República Federal do nosso país. Desse modo, é importante que a comunidade escolar passe a ter um olhar diferenciado para o patrimônio educativo guardando e preservando, uma vez que a memória é um direito dos cidadãos e a escola deveria ser uma das guardiãs da memória das comunidades.
\end{abstract}

PALAVRAS CHAVE: Cidade Mineira Velha. História da Educação. Patrimônio Educativo. História das Instituições Escolares. Patronos.

ABSTRACT: This article aims to understand the reasons that led the Municipal School Padre Carlos Wecki, to honor a priest as a patron, considering that it is a public school. The study has the following objectives: to discuss on the importance of preserving the heritage education for the school community; to understand the creation of the Bairro Cidade Mineira Velha in which is situated the school, and also to trace a brief history of

\footnotetext{
${ }^{1}$ Graduada em Pedagogia da Universidade do Extremo Sul Catarinense (UNESC). gra@ unesc.net

${ }^{2}$ Mestre em Educação pela Universidade Federal de Santa Catarina (1997) e Doutora em Educação pela Universidade Federal do Rio Grande do Sul (2008). Professora titular da Universidade do Extremo Sul Catarinense (UNESC). gra@unesc.net

Saberes Pedagógicos, Criciúma, v. 1, n², julho/dezembro 2017.- Curso de Pedagogia- UNESC
} 


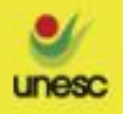

the school. It is a documentary research, and it has as sources the school politicalpedagogic project (PPP), the book "Cidade dos Mineiros" from Dirlene Brunelli, Clemente Borges and Luiz Lima, and other school documents, such as, photographs and newspapers. To put in evidence, the preservation of the school property where the school should be seen as a knowledge building space, and an identity space. These spaces can only be known with the preservation of the school history. On the other hand, this paper presents, based on the documents found, traces forgotten over time that tell the history of the neighborhood and school, and discuss why Padre Carlos Wecki continue in the school community memory. All this so, that the school's history could remain alive in people's memory.

KEYWORDS: Cidade Mineira Velha. History of Education. Educational Heritage. History of School Institutions. Patrons.

\section{INTRODUÇÃO}

Este artigo tem como objetivo compreender os motivos que levaram a Escola Municipal Padre Carlos Wecki, a homenagear um Padre como patrono, mesmo tratando-se de uma escola pública. O estudo tem como objetivos específicos: discutir a importância da preservação do patrimônio educativo para a comunidade escolar, compreender a criação do Bairro Cidade Mineira Velha no qual está situada a escola, e ainda traçar uma breve história da escola.

O tema a ser investigado surgiu quando comecei a fazer parte do quadro de funcionários do referido estabelecimento, em 2013. Fui contratada pela Prefeitura Municipal de Criciúma (PMC) como estagiária (estágio não obrigatório) e ali permaneci até 2014. Quando entrava na escola sempre me deparava com a fotografia do Padre Carlos Wecki e me perguntava por que ela estava ali e, dialogando com os profissionais percebi que eles não sabiam e não conheciam a história do educandário. As experiências que vivi na escola também me instigaram a pesquisar a trajetória desta instituição, uma vez que acredito que a reconstrução e a preservação da história da instituição escolar é algo que precisa ser valorizado, principalmente pela comunidade escolar.

Ao iniciar as pesquisas percebi que o Bairro Cidade Mineira Velha surgiu de um planejamento das mineradoras da região de construir uma vila operária para seus funcionários, essa vila se chamaria "Cidade dos Mineiros" e como nem tudo ocorreu como planejado o local construído passou a se chamar Cidade Mineira Velha.

Saberes Pedagógicos, Criciúma, v. 1, n², julho/dezembro 2017.- Curso de Pedagogia- UNESC 
Revista do Curso de Graduação de Pedagogia - Unesc

Durante a busca de documentos, percebi que a escola não possui o hábito de conservar documentos, objetos, etc. referente à sua trajetória histórica. A busca por documentos bem como a história da instituição, remete a cultura do descarte, onde tudo pode ser jogado fora, substituído. E que por sinal estamos vivendo há muito tempo. "Os arquivos escolares motivam profundas preocupações relativas à salvaguarda e preservação dos seus documentos, que constituem instrumentos fundamentais para a história da escola e a construção da memória educativa.” (MONGARRO, 2005, p.3).

Diante de poucos documentos, os únicos que serviram de apoio para a pesquisa foram os Livros Ponto e o Projeto Político Pedagógico da escola Municipal Padre Carlos Wecki de 2016. Este último traz um relato sobre a trajetória da escola e do bairro, sendo que esse é reformulado todo ano pelo grupo docente da escola.

Além dos poucos documentos encontrados, foram também utilizadas fotografias encontradas no Projeto Político Pedagógico da escola, e no livro Cidade dos Mineiros, publicado em 2014, que tem como autores Dirlene Brunelli, Clemente Bores e Luiz Lima, obra que por sua vez foi muito útil para a compreensão da trajetória do bairro e da escola. O livro traz informações e imagens sobre o Bairro desde sua fundação, bem como educação, lazer, economia, trabalho, religião, história dos moradores, primeiros moradores entre outros aspectos significativos.

O patrimônio educativo oportuniza uma ampla opção de estudo em relação às identidades vividas na escola, que por sua vez são inúmeras, dando visibilidade as mesmas que em muitas situações são silenciadas, esquecidas ou até não valorizadas pela história oficial. Conhecer um pouco do meio onde muitas pessoas passaram e deixaram suas marcas se torna gratificante e necessário. Diante disso Mogarro (2013, p.97), destaca que é preciso,

[...] constituir um novo impulso no estudo do património educativo, estabelecendo a convergência entre os seus elementos constituintes e factores diversos que com eles se articulam, no cruzamento de movimentos que vêm do passado e chegam até nós, entrelaçando-se com os desafios do presente. $[\ldots]$. 
Revista do Curso de Graduação de Pedagogia - Unesc

Portanto, espero contribuir, com este artigo para o registro da história do bairro e da escola na qual fui tão bem acolhida e onde adquiri muitas experiências, tanto para a vida profissional quanto para a vida pessoal.

Em um breve levantamento dos Trabalhos de Conclusão de Curso até o momento defendidos no Curso de Pedagogia de 2003 a 2015, não foi encontrado nenhum trabalho que abordasse o tema em questão, ou seja, "O Bairro Cidade Mineira Velha e a construção da E.M.E.I.E.F (Escola Municipal de Ensino Infantil e Ensino Fundamental) Padre Carlos Wecki”. Entretanto, outros trabalhos no campo da História das Instituições escolares já foram defendidos, como: História, memória, educação e inclusão: a escola municipal prof. Moacyr Jardim de Menezes na vida de crianças com necessidades especiais, de Cinara Lino Colonetti (2008); História da Implantação do Centro Interescolar de Segundo Grau "Abílio Paulo" - Criciúma SC (1975-1979), de Luciane de Mello Alexandre (2009); História da instituição de Educação Especial Diomício Freitas, de Nayana Setubal Bittencourt, (2009); A Contribuição das Irmãs Beneditinas da Divina Providência para a Educação Infantil em Criciúma: "Casa da Criança General Osvaldo Pinto da Veiga" (1959-1969) de Zeli Fernandes da Silva, (2011); A Pedagogia Missionária na E.E.B. Julieta Torres Gonçalves (1968-1985), de Fernanda Bortolotto de Souza (2012); A história do CEI AFASC Carmela Benedet Casagrande, de Patrícia Eufrasio Kurtz (2015); A escola étnica alemã de Forquilhinha (SC) e os primeiros professores: lembranças de ex-alunas (1915-1940) de Caroline Steiner Sartor (2012).

O estudo que resultou neste artigo está relacionado à linha de pesquisa "Fundamentos da Educação", mais especificamente ao eixo temático "História da Educação" do Curso de Pedagogia da Universidade do Extremo Sul Catarinense (UNESC). Este estudo é resultado de uma pesquisa descritiva e exploratória, com abordagem qualitativa. Além disso, é do tipo documental, pois tem como fontes o PPP da escola, o livro Cidade dos Mineiros de Dirlene Brunelli, Clemente Borges e Luiz Lima, e outros documentos escolares como fotografias, jornais e escritos sobre a história do bairro. Para Ludke, (1986) a pesquisa documental é pouco explorada, mas é 
uma técnica muito valiosa de abordagem de dados qualitativos, tanto para complementar a pesquisa como para desvendar aspectos novos.

$\mathrm{Na}$ primeira parte deste artigo trago uma discussão teórica sobre a preservação do patrimônio escolar no campo da história da educação. A escola é um local, no qual se pode encontrar inúmeras identidades vividas, ou seja, é um espaço muito importante a ser lembrado e guardado não só na memória pessoal, mas de forma que as gerações possam ter contato quando o local não for acessível ou não existir. Na segunda parte, busco analisar de que forma se constitui o Bairro Cidade Mineira Velha, tendo como uma das principais fontes o livro Cidade dos Mineiros. Já na última parte, vou tratar da história da E.M.E.I.E.F Padre Carlos Wecki e da escolha de seu patrono.

\section{PRESERVAÇÃO DO PATRIMÔNIO EDUCATIVO NO CAMPO DA HISTÓRIA DA EDUCAÇÃO}

A preservação do patrimônio educativo vem se destacando no campo de pesquisas, pois de fato, essa preservação do patrimônio educativo colocada em prática serve para que a história da educação continue a ser estudada, interpretada e reconstruída. Sobre isso Souza (p.213, 2013) aponta que:

[..] As justificativas para se preservar o patrimônio escolar tendem a reiterar a importância da conservação da memória da escola, remetendo a seus vínculos com a formação da infância e da juventude e a espaço de transmissão de cultura e processos de construção de subjetividades e de identidades. Outra argumentação frequentemente ressaltada é a importância da salvaguarda das fontes de pesquisa para as investigações em história da educação.

Percebe-se que as instituições de ensino integram de maneira significativa a comunidade e detém parte das identidades deste lugar, portanto reconstruir sua história é fortalecer a identidade da comunidade escolar. Contudo, poucos reconhecem o valor do patrimônio educativo, vidas se formam e crescem dentro da escola, mas tudo parece não ter importância quando se trata de história. No entanto, esta mesma sociedade que descarta apresenta “gestos de guardar", como aponta Abreu e Chagas (2009, p. 15): 
Nunca se colecionou tanto, nunca se arquivou tanto, nunca tantos grupos se inquietaram tanto com os temas referentes à memória, patrimônio e museus. Paradoxalmente, os gestos de guardar, colecionar, organizar, lembrar ou invocar antigas tradições vêm convivendo com a era do descartável, da informação sempre nova, do culto ao ideal de juventude.

Hoje tudo parece ter hora e data marcada para acabar, tudo acontece em velocidade máxima, as pessoas já não possuem tempo pra reconhecer o que realmente tem valor. Segundo Von Simson (2000), a velocidade em que estamos vivendo e a rapidez no qual obtemos informações, faz com que o ser humano não saiba discernir as informações que recebe e acaba por perder as lembranças mais importantes.

Com o avanço da tecnologia e sua chegada ao espaço escolar, os documentos e as fotografias, quando guardadas, ficam em pastas anexadas em computadores, sem acesso. Coisas novas vão surgindo e o que fez parte da história de muitas vidas, é descartado. Alguns documentos históricos até são armazenados, mas em qualquer canto da instituição e ali ficam esquecidos e acabam sendo destruídos pelas intempéries do tempo.

\begin{abstract}
Amontoados em porões, debaixo de escadas, em salas apertadas, distribuídos ao acaso em armários e caixas, descuidados e sem interesse, documentos, quase sempre administrativos, além de coleções de instrumentos científicos, livros didáticos, móveis antigos, troféus, medalhas, entre outros objetos, sobrevivem a intempéries, goteiras, condições de insalubridade, falta de identificação, organização e armazenamento adequado na maioria das escolas. (SOUZA, 2013, p. 7).
\end{abstract}

Segundo Souza (2013), atualmente há muitos estudos com iniciativas de preservação do patrimônio escolar, porém existem ainda alguns obstáculos a serem vencidos; tais obstáculos referem-se à escola que não está preparada para valorizar e manter as pesquisas, algumas pesquisas referem-se as mesmas coisas e não chegam a lugar algum.

Embora os obstáculos para preservar a história do patrimônio educativo sejam muitos, há pessoas preocupadas com a história que enxergam além e percebem a escola como espaço de cultura e história pertinente. Paoli (1992) destaca que uma sociedade sem cidadania não vê importância na história do seu próprio passado. Ele Saberes Pedagógicos, Criciúma, v. 1, n² , julho/dezembro 2017.- Curso de Pedagogia- UNESC 
Revista do Curso de Graduação de Pedagogia - Unesc

entende que tudo pode ser aniquilado e substituído. A destruição e a não valorização do patrimônio escolar onde a cidadania também é formada, salienta ainda a tendência de trocar tudo que é "velho" por novo.

Fortalecer a cidadania, ou seja, exercitar os direitos e deveres é respeitar a história, garantindo o cuidado com a memória. Pois traços que sobreviveram do passado, fortalecem a identidade e da voz ao povo.

O patrimônio escolar também pode ser comparado ao patrimônio industrial, que também vem ganhando pesquisas recentemente, pois ambos são lugares de memória. Nos dois casos citados, ocorrem substituições, por exemplo: na escola substituem-se práticas pedagógicas, prédios, objetos e nas empresas: máquinas, modelos de trabalho, prédios, funções. Embora diferentes, as duas impulsionam o país, pois não há crescimento em país algum sem educação e não há educação sem escola, assim como não há progresso sem trabalho, sem indústrias. Sobre isso ressalta Ferreira (2009, p.13): "entretanto, é fundamental entender que esses elementos de origem material não se dissociam daqueles de caráter imaterial. Assim pessoas e máquinas, saberes e fazeres se entrecruzam e disso deriva, talvez, outra possibilidade patrimonial."

Conhecer e preservar a história da escola é algo de grande importância que, infelizmente, as pessoas não se dão conta, embora, todos que trabalham e frequentam a escola tem esse direito, ou seja, "o direito ao passado" como anuncia Paoli (1992).

Zancul (2015) ressalta que ainda é preciso fazer muito pela preservação e estudo do patrimônio educativo, muitas coisas ainda precisam ser desveladas, pois fogem do nosso olhar. Essa preservação precisa ser reconhecida em toda área da educação, nas universidades, secretarias, etc. E ainda, cabe a cada grupo organizar práticas de preservação que assegurem a manutenção e memória das instituições.

Assim sendo, a preservação do patrimônio possibilita reviver as memórias dos que perderam a voz e a vez, assim reconhecendo que o resgate da história, apoia as experiências dos oprimidos e faz com que as pessoas percebam que o poder deseja calar o povo, destruindo o que faz parte da sua história. 


\title{
SABERES PEDAGÓGICOS
}

Revista do Curso de Graduação de Pedagogia - Unesc

Conhecer alguns aspectos da história da Escola Municipal de Educação

Infantil e Ensino Fundamental Padre Carlos Wecki implica em contextualizar sua criação, a começar pela emergência do Bairro Cidade Mineira.

\subsection{Breve história do Bairro Mineira Velha}

Em 1957 surgiu uma sugestão do Sindicado de Mineradores, ou seja, o órgão representante dos donos das minas de carvão, de construir uma vila. A idealização da edificação de casas visava construir uma vila com toda a infraestrutura necessária para atender os trabalhadores das minas de carvão da cidade de Criciúma e assim mantê-los próximos às empresas mineradoras. O prefeito de Criciúma, na época Addo Caldas Faraco, unido com outros segmentos conseguiu o financiamento de 100 casas. Essas casas foram construídas para os trabalhadores e financiadas de forma que pudessem pagar durante alguns anos (BRUNELLI; BORGES; LIMA, 2014).

No PPP há registros sobre a fundação do Bairro:

[...] Do projeto constavam amplas avenidas e ruas, jardins de infâncias e escolas, áreas verdes e praças, áreas para serviços de saúde, 'era uma sofisticação para época', locais pré-determinados para a construção de supermercados. A ocupação das unidades residenciais deveriam ter sido resultado de estudo levantado por assistentes sociais que, a pedido das empresas mineradoras, pesquisaram as necessidades da massa operária que gostaria de residir nesse bairro. (ESCOLA PADRE CARLOS WECKI, 2016, p.12)

Fernando Jorge da Cunha Carneiro ${ }^{3}$ foi o arquiteto que planejou a cidade dos mineiros. Segundo Brunelli, Borges e Lima (2015, p.15):

\begin{abstract}
Após a decisão de se implantar a Cidade dos mineiros, as mineradoras São Marcos, Boa Vista, Metropolitana, Catarinense e União compraram 170 hectares de terras que seriam destinados ao projeto, doando-as para implantação do loteamento. As terras pertenciam ás famílias de Arcângelo Meller, Afonso Zanette e Fortunato Simão (Simon). O local escolhido ficava próximo ao bairro Mina União, onde havia uma estrada de ferro que chegava até ali para carregar o cravão.
\end{abstract}

\footnotetext{
${ }^{3}$ Primeiro Arquiteto catarinense registrado no CREA, participou da criação de entidades de educação, sociedades recreativas, atividades artísticas, e umas tantas outras determinantes na melhoria da vida do sul. (CARNEIRO, 2012)

Saberes Pedagógicos, Criciúma, v. 1, n², julho/dezembro 2017.- Curso de Pedagogia- UNESC
} 
Figura 1: Projeto do original loteamento Cidade dos Mineiros

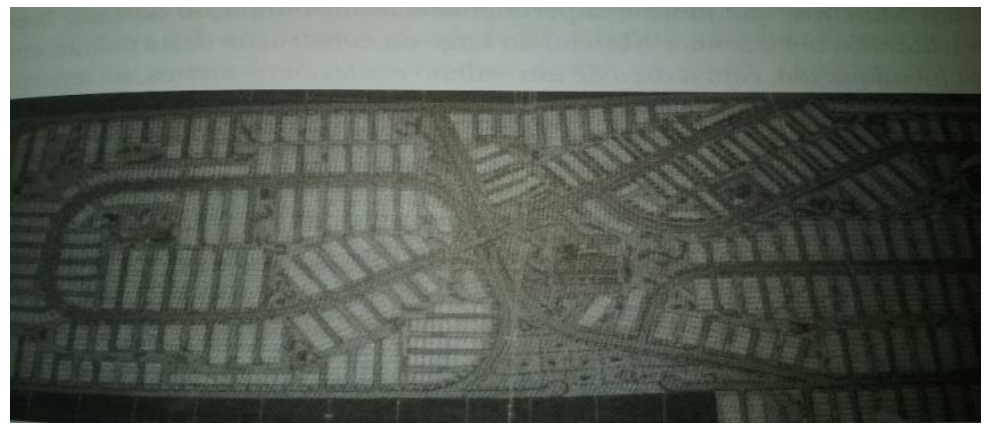

Fonte: Brunelli, Borges e Lima (2014, p.15)

Também se pode citar a matéria do Jornal Tribuna Criciumense (1957, p.2):

Conforme é de conhecimento público, estiveram na Capital Federal, há poucos dias, o arquiteto Dr. Fernando Carneiro, que projetou a <cidade dos mineiros $>$, os Srs. Ado Caldas Faraco, Prefeito Municipal e o Sr. Pedro Andrade, interventor do Sindicato dos Mineiros, que junto à superintendência da Fundação da Casa Popular estiveram tratando com o Sr. Marcial do Lago, da construção dessa cidade, em terreno que já foi adquirido, com o ares de um milhão e seiscentos metros. [..].

O projeto do loteamento não chegou a ser finalizado, algumas casas já estavam prontas, porém, foram abandonadas antes mesmo da entrega. "Então, liberados por políticos com aval do prefeito, as casas foram invadidas ${ }^{4}$, e o projeto do arquiteto Fernando Carneiro começou a ruir.” (BRUNELLI; BORGES; LIMA, 2014, p.12).

De acordo com o PPP da escola "O bairro não tinha infraestrutura nenhuma, não havia água, energia elétrica, sistema de esgoto, as ruas não eram pavimentadas." (ESCOLA PADRE CARLOS WECKI, 2016). Apesar de não ter infraestrutura no local, muitas famílias viram ali uma oportunidade de viver e de criar os filhos e filhas.

Brunelli, Borges e Lima (2014) afirmam que mais tarde foram construídas mais 500 casas, dando continuidade a segunda parte do projeto. O conjunto das

\footnotetext{
${ }^{4}$ No livro de Brunelli, Borges e Lima (2014), o termo encontrado é invasão, no entanto, se considerarmos que a moradia é um direito das pessoas, o melhor termo a ser utilizado seria ocupação.
}

Saberes Pedagógicos, Criciúma, v. 1, n², julho/dezembro 2017.- Curso de Pedagogia- UNESC 
primeiras casas passou a ser denominada Cidade Mineira Velha e, o das casas novas, Cidade Mineira Nova. Desse modo, os hectares que foram determinados para construir a Cidade dos Mineiros se transformaram em três bairros: Cidade Mineira Velha, Cidade Mineira Nova e ainda Vila Manaus. Cabe lembrar que a Escola Municipal de Educação Infantil e Ensino Fundamental Padre Carlos Wecki está situada na Cidade Mineira Velha.

A principal atividade econômica do município na época era a mineração, que foi durante muito tempo fonte de trabalho e se tornou uma importante fonte de renda para inúmeras famílias de agricultores e de pessoas vindas de outras cidades da região. Na década de 1960 o município contava com várias empresas ligadas à exploração do minério.

De acordo com Rabelo (2007, p.38):

[...] como consequência do crescimento do complexo carbonífero, houve a geração de muitos empregos, exigindo das empresas a criação de inúmeras vilas operarias, a fim de atrair, fixar, mas também manter sob controle a mãode-obra operária. Eram trabalhadores chegando constantemente com suas famílias, num curto espaço de tempo, levando a construção das vilas a empreender um ritmo comparável ao de uma linha de produção [..].

Segundo Carola (1997), com o processo da Revolução Industrial, já não bastava manter o domínio dos trabalhadores nas minas de carvão, seria necessário que as moradias fossem perto do trabalho para facilitar o cotidiano prático dos trabalhadores.

As vilas operárias faziam parte do complexo carbonífero, "Este, por sua vez, era constituído por companhias carboníferas, ferrovia, lavador de carvão, termoelétrica, carboquímica e porto.” (RABELO, 2007, p.39).

Brunelli, Borges e Lima (2014) destacam em sua obra que o carvão trouxe muitas vantagens para a população do Bairro Cidade Mineira Velha e comunidades vizinhas, mas também trouxe muitos problemas. Quanto mais as minas se multiplicavam, maior era o impacto ambiental na cidade e região, assim como doenças respiratórias, entre outras. 
As minas de carvão geraram muitos empregos na região. Segundo Fortunato (2008) a "região carbonífera", era um local muito procurado por trabalhadores, pois a região passou a ser conhecida como lugar de desenvolvimento urbano.

Hoje na cidade de Criciúma e região já não há mais tantas empresas de mineração como na época da fundação do bairro, na medida em que as minas de carvão foram fechando os moradores foram buscar outros tipos de emprego. Antes mesmo do fechamento da maior parte das mineradoras ${ }^{5}$ outros setores da economia foram surgindo. Cerâmicas de azulejo, plástico e empresas de confecção passaram a ocupar lugar de destaque na economia de Criciúma, lugar antes ocupado pela mineração.

Em função dos processos de crise por que passou a Região Carbonífera, os empresários observaram a necessidade de diversificação das atividades produtivas e impulsionaram diversos setores econômicos, entre eles, a cerâmica, o calçadista, o plástico, vestuarista, metal-mecânico, a construção civil. E como conseqüência da diversificação dos diversos setores produtivos, Criciúma passa a 41 ser um centro de atração populacional, contribuindo para a ampliação e transformação do espaço urbano, sendo conhecida hoje como 'Pólo Criciúma'. (FORTUNATO, 2008, p. 40 -41).

Segundo Colossi, (2005, p. 19):

Criciúma cresceu com esse modelo de desenvolvimento, em que antigamente as glebas coloniais e a atividade eminentemente agrícola deram espaço à extração de carvão mineral, não havendo preocupações com a infra-estrutura urbana futura. A atividade mineradora foi a moduladora do espaço urbano e modificador do espaço natural, destruindo a paisagem e os recursos hídricos da região, ou seja, alterando a paisagem natural.

O bairro Cidade Mineira Velha constitui-se juntamente com outros bairros o município de Criciúma, sendo que o município destaca-se entre os mais populosos do estado de Santa Catarina. Os bairros construídos em Criciúma em torno das atividades carboníferas foram ganhando espaço, alguns continuam com suas características originais e outros foram bastante alterados.

\footnotetext{
${ }^{5}$ A partir da década de 1980, a mineração teve que enfrentar uma grande crise, essa crise se dava pela competição com o carvão importado e atuação das organizações ambientais. Este período trouxe a pior crise do carvão em Santa Catarina. Lúcio, 2009 (apud CAROLA, 2002).
}

Saberes Pedagógicos, Criciúma, v. 1, n², julho/dezembro 2017.- Curso de Pedagogia- UNESC 


\section{SABERES PEDAGÓGICOS}

Revista do Curso de Graduação de Pedagogia - Unesc

Nos tempos áureos da exploração do carvão, os moradores do bairro utilizavam-se do futebol e das danças nos finais de semana como lazer. Como destaca Brunelli, Borges e Lima (2014), em cinco de outubro de 1962 foi fundado o Grêmio Recreativo Esportivo Cidade Mineira, que mais tarde passou a se chamar Associação Recreativa e Esportiva Cidade Mineira Velha, que servia para que os times de futebol pudessem se encontrar e ali jogar.

Ainda nos momentos de lazer as pessoas do bairro Cidade Mineira Velha, em meados da década de 1960, se encontravam nas missas realizadas na igreja local, nos bailes de final de semana e nos jogos de futebol. No livro "Cidade dos Mineiros" os autores Brunelli, Borges e Lima (2015, p. 112-113) também destacam a diversão infantil da época.

Apesar das dificuldades e problemas financeiros, as crianças se divertiam. A maioria dos moradores alega ter tido uma infância feliz. As brincadeiras de rua eram muitas: catavam fichinhas, jogavam bola, taco, bocha, brincavam de ré, bolinha de gude, pião, ourinho, peteca... Ao final da tarde, os pais se sentavam em frente às casas e conversavam, enquanto os filhos brincavam de roda, cirando, ovo choco... Brincadeiras inocentes e sadias [...]

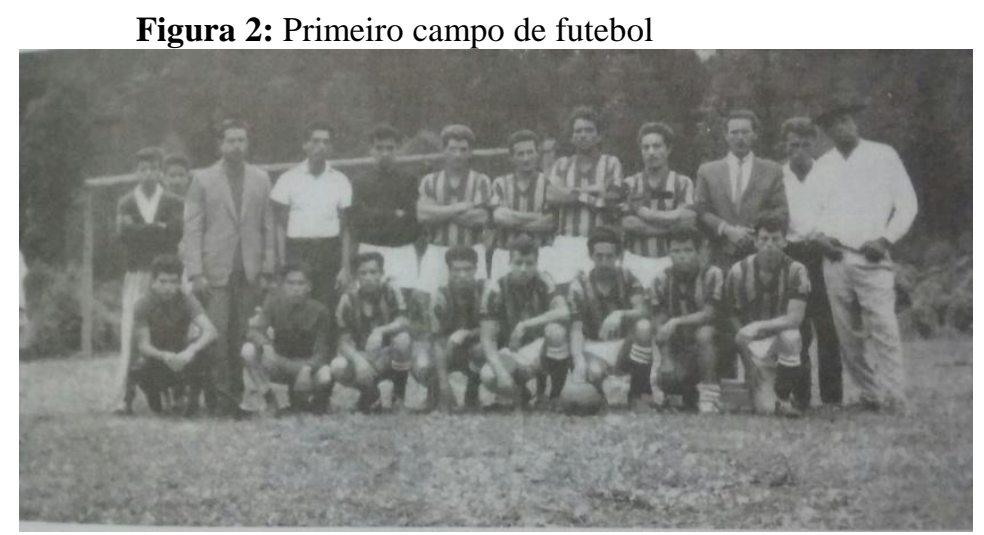

Fonte: Brunelli, Borges e Lima (2014, p.85)

Nota-se que o bairro Mineira Velha e as pessoas que ali vivem, possuem muitas lembranças do passado de uma cultura que foi forjada no cotidiano das pessoas que ali viveram. Lembrar, registar, guardar a história é reviver lembranças quando apetecer, e quantas vezes forem necessárias. Von Simson (2000, p.66) ainda desta que:

Saberes Pedagógicos, Criciúma, v. 1, n², julho/dezembro 2017.-Curso de Pedagogia- UNESC 
Podemos acrescentar que o ato de relembrar em conjunto, isto é, o ato de compartilhar a memória, é um trabalho que constrói sólidas pontes de relacionamento entre os indivíduos - por - que alicerçadas numa bagagem cultural comum - e, talvez por isso, conduza à ação. Portanto, a memória compartilhada é tanto forma de domar o tempo, vivendo-o plenamente, como empuxo que nos leva à ação, constituindo uma estratégia muito valiosa nestes tempos em que tudo e transformado em mercadoria, tudo possui valor de troca.

Esta breve história do bairro Cidade Mineira Velha teve como objetivo apresentar algumas informações sobre o local no qual foi fundada a E.M.E.I.E.F Padre Carlos Wecki. No item seguinte procuro analisar o que motivou a construção do educandário, bem como os motivos que levaram a escola homenagear o Padre Carlos Wecki como patrono. Apresento também uma breve biografia do pároco.

\subsection{A Escola Municipal Padre Carlos Wecki e seu patrono}

A primeira escola nas proximidades da Cidade dos Mineiros foi criada em 1966 e se chamava escola Professor Marcilio Dias de San Thiago ${ }^{6}$. Na época "formouse uma comissão de moradores para solicitar à Prefeitura a criação de uma escola na Cidade dos Mineiros.” (BRUNELLI; BROGES; LIMA, 2014, p. 68).

Segundo Brunelli, Borges e Lima (2014), a comissão de moradores foi até a prefeitura fazer o pedido de uma escola para o prefeito Ruy Correa Hülse ${ }^{7}$, que autorizou a realização de um levantamento para verificar a real necessidade uma escola no local.

Já na década de 1990, a população da região do bairro vinha aumentando e consequentemente, o número de crianças que precisavam frequentar as escolas, contudo a escola mais próxima não ficava perto do bairro, as crianças necessitavam de transporte para levá-los até lá. Foi nesse momento que surgiu a necessidade de se construir outra escola, essa então no bairro que hoje se chama Cidade Mineira Velha. A escola foi

\footnotetext{
${ }^{6}$ Esta escola existe até hoje em funcionamento e tem a denominação de Escola Municipal de Educação Infantil e Ensino Fundamental Prof Marcilio Dias de San Thiago e está situada no Bairro Vila Manaus.

${ }^{7}$ Foi prefeito de Criciúma entre os anos de 1966 a 1970.

Saberes Pedagógicos, Criciúma, v. 1, n², julho/dezembro 2017.- Curso de Pedagogia- UNESC
} 
Revista do Curso de Graduação de Pedagogia - Unesc

criada por Lei Municipal, No. 2.997 de 13 de Outubro de 1994, conforme o excerto que segue:

Art. 10. - Fica denominado GRUPO ESCOLAR "PADRE CARLOS WECKI", a escola da Rede Municipal de Ensino, situada na localidade de Cidade Mineira Velha, criada pelo Decreto No. 236/AS/94, datado de 24.03.94. (CRICIÚMA, 1994).

Figura 4: Grupo escolar Padre Carlos Wecki (1995)

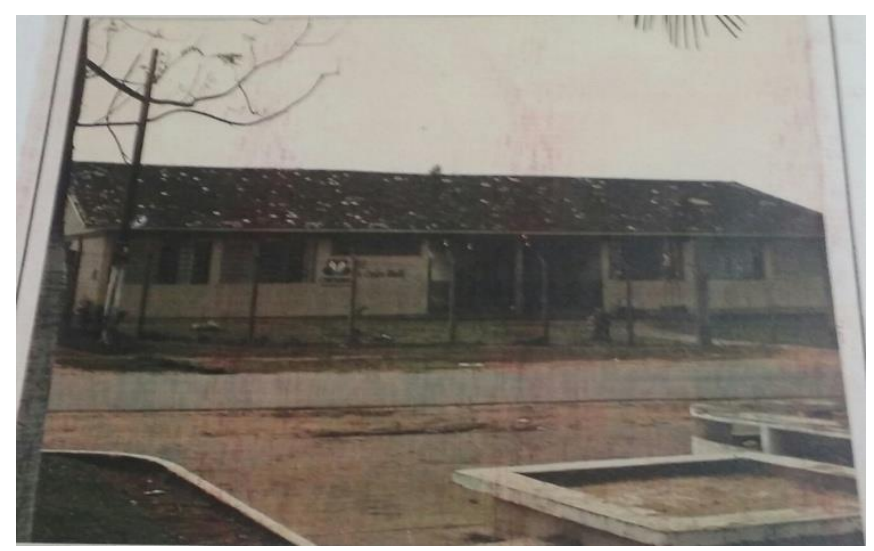

Fonte: Projeto Político Pedagógico da escola Padre Carlos Wecki (2016)

Nessa época o prefeito de Criciúma era Eduardo Pinho Moreira ${ }^{8}$, e a escola em questão foi construída em frente à igreja e ao posto de saúde, e de acordo com o registro do PPP, em sua fundação o prédio do educandário possuía 4 salas, 12 funcionários entre eles professores, serventes, auxiliar e diretor, além disso, atendia 158 alunos (ESCOLA PADRE CARLOS WECKI, 2016).

Ainda, segundo o PPP, foram diretores do educandário desde sua fundação: Albertina de Oliveira Michelon (1994-1996), Marlene Souza Barbosa (1997-1999), Juçara Maria Silvano Gonçalves (2000), Reginaldo de Oliveira Bernardo (2001-2004), Rosélia Tertuliano (2005-2006), Marissilva Medeiros Barp (2006), Reginaldo de Oliveira Bernardo (2007) (ESCOLA PADRE CARLOS WECKI, 2016).

Nas anotações das horas de trabalho do dia 22 de fevereiro de 1995 há registros de algumas das primeiras professoras da época: Judite Gonçalves, Adriana

\footnotetext{
${ }^{8}$ Foi prefeito de Criciúma entre os anos de 1993 a 1996

Saberes Pedagógicos, Criciúma, v. 1, n², julho/dezembro 2017.- Curso de Pedagogia- UNESC
} 


\section{SABERES PEDAGÓGICOS}

Revista do Curso de Graduação de Pedagogia - Unesc

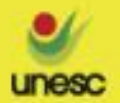

Unehos Acadgnioa

de humsridadec,
Clenciate toucticis

Cechinel Bonfante, Fátima Vieira Paulo, Janete Bett, Ieda Elias de Oliveira, Adriano Ferro, Maria Juraci de Souza, Sulamita Cardoso, Eloiza Ronconi (ESCOLA PADRE CARLOS WECKI, 1995).

Hoje na instituição a equipe diretiva é constituída pelos professores Rosânia Maria Silvano Bittencourt (Diretora) e Tomázia Alexandra Barros Martinhago, Daniela Maccarini Martinhago Ribeiro e Ivonilson Alves Magalhães (Auxiliares de Direção). Ao todo são 40 funcionários entre eles, professores da educação infantil, ensino fundamental, letramento, artes, educação física, informática, inglês e professores do atendimento educacional especializado (AEE), estagiários, monitores e serventes (ESCOLA PADRE CARLOS WECKI, 2016).

Atualmente a escola possui 14 salas de aulas, sala de diretoria, sala de secretaria, sala de professores, laboratório de informática, biblioteca, sala de recursos multifuncionais para Atendimento Educacional Especializado (AEE), cozinha, parque infantil (ESCOLA PADRE CARLOS WECKI, 2016). A faixa etária das crianças que estudam no educandário é de quatro e cinco anos em período integral e parcial, e também alunos do $1^{\mathrm{o}}$ ao $5^{\circ}$ ano do Ensino Fundamental no período matutino e vespertino. A escola funciona no período matutino das 07:50 às 11:50 e no período vespertino das 13:00 às 17:00. Em relação aos professores, a maioria possui graduação e pós-graduação (ESCOLA PADRE CARLOS WECKI, 2016).

A estrutura física da escola é constituída por três blocos: o bloco da Educação Infantil, o bloco do Ensino Fundamental e o bloco das salas de artes e informática. Mas, nem sempre foi assim, a escola foi fundada como Grupo Escolar Padre Carlos Wecki para atender somente o Ensino Fundamental. Mais tarde, mais precisamente em 2011, a Associação Feminina de Assistência Social de Criciúma (AFASC) doou o bloco ao lado da escola que foi incorporado a escola e a partir daí a educação infantil também passou a ser atendida no educandário 9 .

Figura 5: Entrada da escola Padre Carlos Wecki (2016)

\footnotetext{
${ }^{9}$ Esta informação foi obtida de maneira informal

Saberes Pedagógicos, Criciúma, v. 1, n², julho/dezembro 2017.- Curso de Pedagogia- UNESC
} 


\section{SABERES PEDAGÓGICOS}

Revista do Curso de Graduação de Pedagogia - Unesc

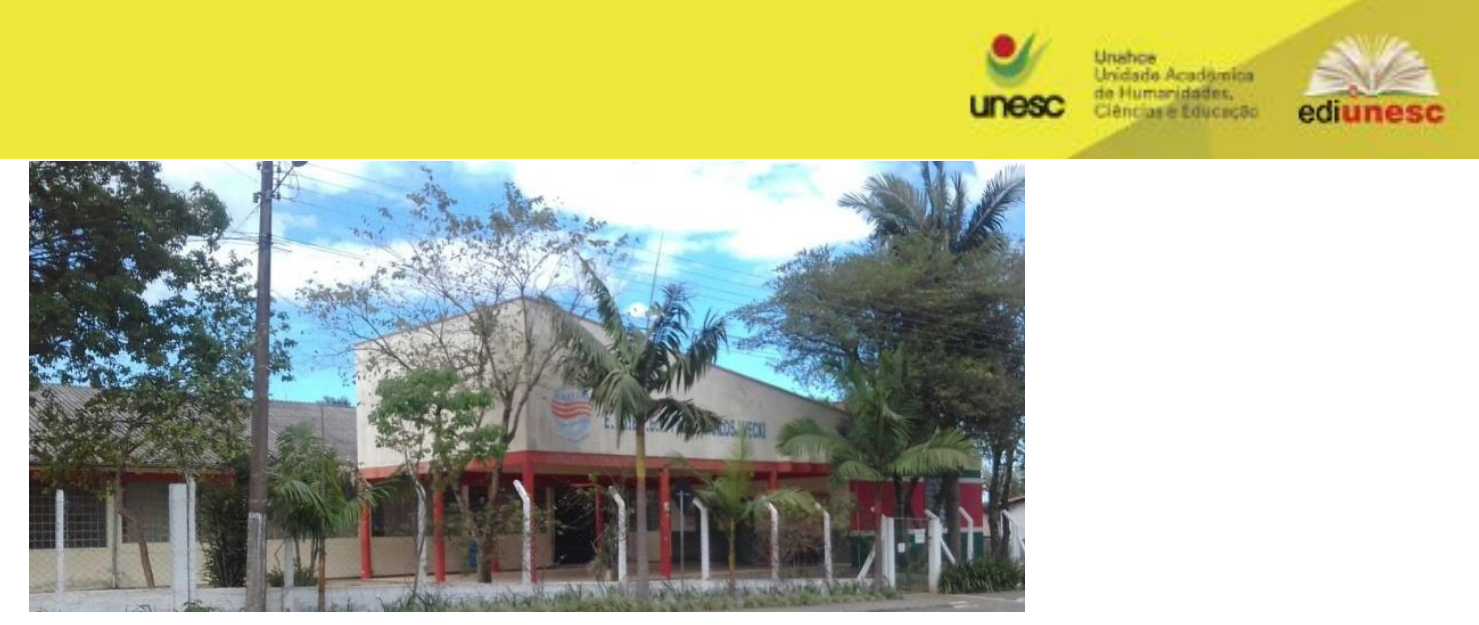

Fonte: Arquivo pessoal da autora

Figura 6: Bloco Educação Infantil (2016)

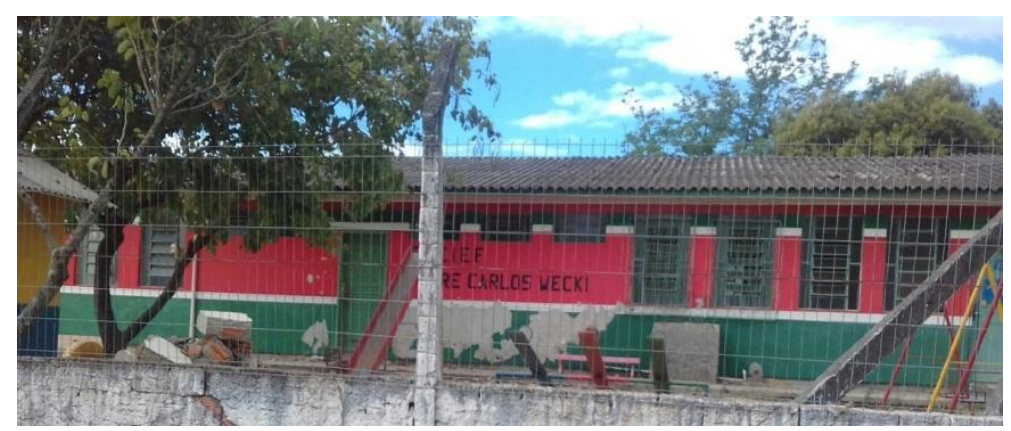

Fonte: Arquivo pessoal da autora

O educandário possui computadores para uso da direção e dos professores e também na sala de informática para uso dos alunos, possui livros didáticos, literários, CD’S, DVD'S, televisão, DVD, data show com tela de projeção. Recursos estes que são utilizados conforme a necessidade dos professores (ESCOLA PADRE CARLOS WECKI, 2016).

Segundo o PPP são parceiros da escola: a comunidade local, a prefeitura municipal, o posto de saúde, a igreja, o comercio local, a associação de moradores, a pastoral da criança, empresas da região, a Comad (Conselho Municipal de Políticas sobre Drogas de Criciúma) a UNESC (Universidade do Extremo Sul Catarinense), e a COPIRC (Coordenadoria de promoção da igualdade racial de Criciúma) (ESCOLA PADRE CARLOS WECKI, 2016).

A escola atende muitas crianças com deficiência e as mesmas recebem o AEE. A mesma possui materiais pedagógicos disponíveis e estagiários que auxiliam a Saberes Pedagógicos, Criciúma, v. 1, n², julho/dezembro 2017.- Curso de Pedagogia- UNESC 
Revista do Curso de Graduação de Pedagogia - Unesc

15

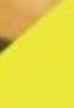

professora regente na aprendizagem desses alunos que frequentam o ensino regular (ESCOLA PADRE CARLOS WECKI, 2016).

Em relação ao nome do educandário, Brunelli, Borges e Lima (2014, p. 80) destacam que "Padre Carlos Wecki foi escolhido como Patrono da escola por ser uma pessoa muito admirada e batalhadora junto à comunidade. Trabalhou na Cidade Mineira de 1977 a 1982."

Como podemos ver Padre Carlos não trabalhou por muito tempo na região do Bairro Mineira Velha, todavia já era conhecido pela maioria das pessoas da comunidade, pois o padre visitava as minas, para rezar junto aos mineiros. "Padre Carlos Wecki era muito conhecido e estimado, e mesmo depois de ter deixado a paróquia Nossa Senhora de Fátima, seus programas radiofônicos continuaram sendo ouvidos pelos moradores da Cidade Mineira." (BRUNELLI; BORGES; LIMA, 2014, p. 259).

Figura 7: Padre Carlos Wecki

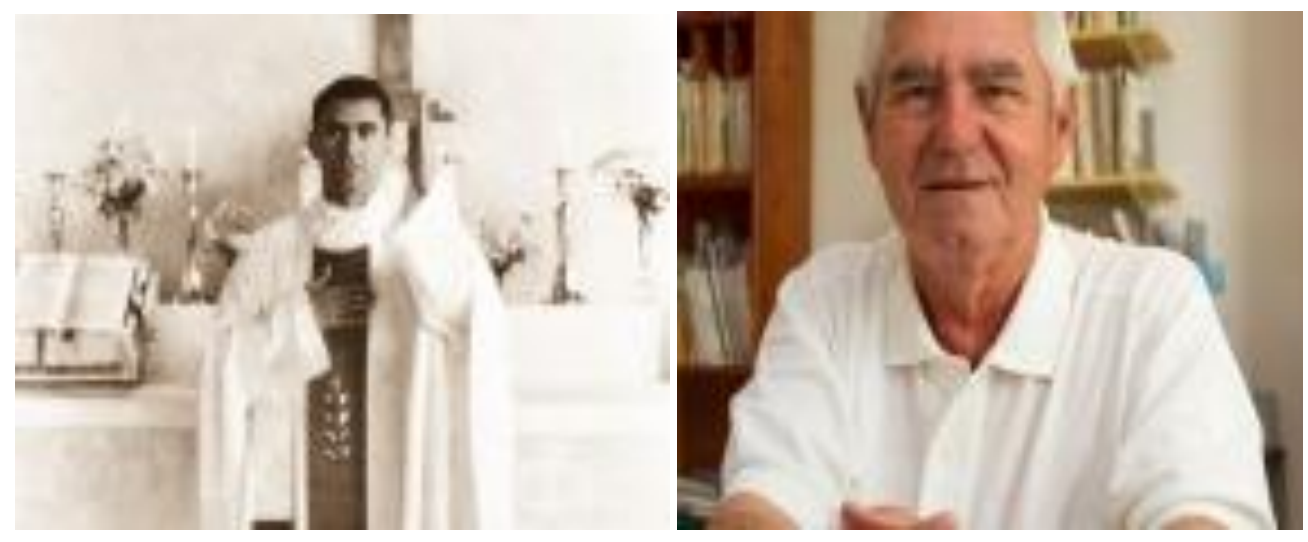

Fonte: (DIOCESE DE CRICIÚMA, 2013, p.1)

Padre Carlos Wecki nasceu em 20 de Novembro de 1933, sua mãe se chama Ana Figueiredo e seu pai José Silvestre Wecki. Dom Anselmo enviou o Padre Carlos Wecki para Criciúma, onde começou seu trabalho na Paróquia Santa Bárbara, na chamada Vila Operária. Na entrevista para o site da Diocese de Criciúma Padre Carlos conta que sua vocação para seguir na vida religiosa surgiu naturalmente, e que quando 
criança sempre ia à igreja com seus pais e achava muito bonito ver o padre rezar a missa (DIOCESE DE CRICIÚMA, 2013).

Nota-se que Padre Carlos Wecki foi um homem muito admirado pela comunidade por trabalhar junto dela, entretanto ficam algumas indagações: Por que foi dado o nome de um religioso a uma instituição pública e laica? Por que foi homenageado ainda em vida? A escola pública desde a proclamação da república tem como características ser laica, ou seja, livre de religiões. Algumas instituições se contradizem quando fazem o uso do nome de algum religioso em eventos, festas e ainda em seus próprios nomes, tornando-os "patronos", porém na Constituição da República Federal do Brasil mais precisamente no artigo 19, consta que:

Art 19. É vedado à União, aos Estados, ao Distrito Federal e aos Municípios: I. estabelecer cultos religiosos ou igrejas, subvencioná-los, embaraçar-lhes o funcionamento ou manter com eles ou seus representantes relações de dependência ou aliança, ressalvada, na forma da lei, a colaboração de interesse público. (BRASIL, 2000, p.29).

Segundo Oliveira (2009), colocar nomes de pessoas para patronos em escolas pode ser um hábito republicano, uma vez que aqueles que realizarem trabalhos, doações e atividades beneficentes, mereciam ser homenageados pelas instituições ou organizações, eternizando assim seus nomes. Ainda sobre os patronos Souza (1998, p. 134) afirma:

\footnotetext{
Para captar recursos em prol das construções escolares, o Estado valeu-se de uma estratégia - a designação do nome da escola àqueles beneméritos que contribuíssem com a causa da instrução pública. Dessa forma, em troca de doação financeira a homenagem eternizada. Instituía-se, dessa forma, a figura do "patrono", personalidade a ser enaltecida e cultuada por professores, alunos e sociedade, especialmente em datas de comemoração do aniversário da escola.
}

De qualquer forma, este entendimento sobre as escolha dos patronos e patronesses das escolas não explica o fato da escola ter o nome de um religioso, uma vez que se trata de uma escola pública municipal e laica, nas prescrições da lei.

\section{CONCLUSÃO}

Saberes Pedagógicos, Criciúma, v. 1, n², julho/dezembro 2017.- Curso de Pedagogia- UNESC 
Ao finalizar essa pesquisa, pude perceber como a preservação do patrimônio educativo é algo importante para a comunidade escolar. Pois é na compreensão da sua história que a escola poderá se manter viva, entendendo que esse processo exige muito mais do que guardar documentos ou fotografias que registrem os acontecimentos considerados os mais importantes do educandário, significa entender que através da reconstrução do passado, que se dá pelos vestígios deixados, é possível extrair experiências passadas que podem iluminar a construção do presente. No entanto, esta escola como boa parte das instituições está tomada pela cultura do descarte, pois muitos documentos já não existem mais, dificultando a reconstrução da sua trajetória e sobre o que motivou a escolha do patrono. Fica nítido que não há o hábito de conservar e preservar o seu patrimônio educativo.

O Bairro Cidade Mineira Velha, se deu a partir do projeto de uma vila operária denominada "Cidade dos Mineiros". As casas que foram propostas no projeto, foram construídas, mas abandonadas antes mesmo da finalização do projeto. Assim ao longo do tempo o terreno destinado ao projeto se transformou em três bairros: Cidade Mineira Velha, Cidade Mineira Nova e Vila Manaus.

Ao conhecer a história do bairro, no qual a escola está situada, percebo a grande importância da mesma nesse local. O bairro é repleto de sujeitos que carregam suas experiências consigo e que constroem as suas histórias e a do bairro. Um fato que evidencia isso e que foi uma fonte importante para este estudo foi a obra intitulada "Cidade dos Mineiros" de autoria de Dirlene Brunelli, Clemente Borges e Luiz Lima. A obra traz acontecimentos significativos, além de depoimentos das pessoas que ali vivem.

Sobre a criação da escola Padre Carlos Wecki em 1994, entendo que a escola foi construída para atender a grande demanda de crianças naquela região que precisavam frequentar a escola, já que a escola mais próxima precisaria de transporte para leva-los. Logo em sua fundação a escola já tinha 158 alunos e só 4 salas para atendê-los. Além disso, foi construída para atender crianças no ensino fundamental, só mais tarde em 2011 passou atender crianças na educação infantil na faixa etária de 4 e 5 Saberes Pedagógicos, Criciúma, v. 1, n², julho/dezembro 2017.- Curso de Pedagogia- UNESC 
Revista do Curso de Graduação de Pedagogia - Unesc

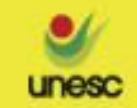

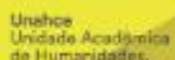

Gienciare toucticas

anos (pré-escola), essa informação foi obtida de modo informal pois nada disso foi encontrado em forma de documento ou registro.

Quanto ao patrono, Padre Carlos Wecki, foi possível observar que ele trabalhou na região da Cidade Mineira Velha de 1977 a 1982 e a escola só foi criada com este nome em 1994, portanto, a homenagem a ele acontece muitos anos depois. Diante disso, podemos supor que o Padre significou muito e deixou marcas, apesar de ter atuado pouco tempo na comunidade. O nome do Padre deve ter sido lembrado pela comunidade escolar em função da forte influência dele na cidade de Criciúma

Um elemento central que contribuiu para a liderança do Padre na cidade foi o fato de ele ter protagonizado um programa radiofônico muito ouvido na cidade e região. O programa ia ao ar nas manhãs de segunda à sexta-feira, tendo como público alvo os fiéis da Igreja Católica. Esta presença constante, pelo rádio, nas casas dos moradores do bairro Cidade Mineira Velha certamente garantiu que o Padre continuasse nas memórias dos mesmos. Esse programa tinha como objetivo aproximar os fiéis nas orações, mas também divulgar informações de utilidade pública, bem como controlar os comportamentos considerados desviantes pela Igreja. Até hoje pessoas da cidade se recordam da música "De Colores", tema de abertura do programa.

Importante lembrar que no início dos anos de 1990 a cidade de Criciúma ainda vivia o rescaldo dos conflitos trabalhistas entre mineiros e mineradores muito fortes nos anos de 1980 em toda região carbonífera. Isso nos leva a pensar que o referido Padre talvez tenha assumido, por meio do programa, um papel de mediador destes conflitos.

Um aspecto que também pode ter sido motivador desta homenagem, mas com menor força, é que muitas escolas públicas de Criciúma e região tem como patrono Padres ou religiosos, talvez pela forte presença da Igreja Católica. Exemplo disso são as seguintes escolas: E.M.E.F. Padre José Francisco Bertero, E.M.E.I.E.F. Padre Ludovico Coccolo, E.M.E.F. Padre Paulo Petruzzellis, E.M.E.I.E.F. Santa Rita De Cássia, E.E.B. Padre Miguel Giacca.

Esta prática evidencia o quanto o estado brasileiro não é laico na sua plenitude, como prescreve a Constituição da República Federal do nosso país. Ainda Saberes Pedagógicos, Criciúma, v. 1, n², julho/dezembro 2017.- Curso de Pedagogia- UNESC 


\section{SABERES PEDAGÓGICOS}

Revista do Curso de Graduação de Pedagogia - Unesc

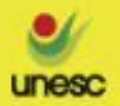

Unehos Acadenion

de Hiumaridadec.

estamos longe dos ideais anunciados com a proclamação da república. As religiões ainda interferem as práticas pedagógicas das nossas escolas públicas. Este fato nos instiga a continuar os estudos para compreendermos um pouco mais sobre a suposta laicidade da escola pública na nossa cidade e região.

Ao chegar ao fim desse estudo, acredito ter contribuído para que os educadores e os que atuam na escola E.M.E.I.E.F Padre Carlos Wecki, passem a ter um olhar diferenciado para os seus documentos, mobílias etc., guardando, preservando o seu patrimônio educativo, uma vez que a memória é um direito dos cidadãos e a escola deveria ser uma das guardiãs da memória das comunidades.

\section{REFERÊNCIAS:}

ABREU, Regina; CHAGAS Mário. Memória e patrimônio: ensaios contemporâneos. 2.ed. Rio de Janeiro: Lamparina, 2009.

BRASIL.; OLIVEIRA, Cláudio Brandão de. Constituição da República Federativa do Brasil. 6. ed Rio de Janeiro: DP\&A, 2000. 335 p.

BRUNELLI, Dirlene et al. A cidade dos mineiros: bairro cidade mineira velha. Criciúma: Coan, 2014. 430 p.

CRICIUMA, Câmera Municipal. Lei No 2997/1994. Disponível em: https://goo.gl/A1ci6O. Acesso em: 14 out. 2016.

CAROLA, Carlos Renato. Dos subterrâneos da história as trabalhadoras das minas de carvão de Santa Catarina (1937-1964). Florianópolis: Ed. UFSC, 1997. 231 p.

COLOSSI, Giuliano Elias. O processo de apropriação do espaço urbano em loteamento populares: um estudo de caso no loteamento cidade dos mineiros Criciúma/SC. 2005. 242 f. Dissertação (Mestrado) - Universidade do Extremo Sul Catarinense, Programa de Pós-Graduação em Ciências Ambientais, 2005 Disponível em: 〈http://www.bib.unesc.net>.

DIOCESE DE CRICIÚMA. Padre Carlos Wecki celebra 50 anos de sacerdócio. 2013. p.1 . Disponível em: https://goo.gl/hs7C71. Acesso em: 01 jul. 2016.

ESCOLA PADRE CARLOS WECKI. Projeto Pólitico Pedagógico. Criciúma, 2016.

ESCOLA PADRE CARLOS WECKI. Livro ponto. 1995.

Saberes Pedagógicos, Criciúma, v. 1, n², julho/dezembro 2017.- Curso de Pedagogia- UNESC 


\section{SABERES PEDAGÓGICOS}

Revista do Curso de Graduação de Pedagogia - Unesc

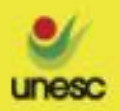

FERREIRA, Maria Leticia Mazzucchi. Patrimônio industrial: lugares de trabalho, lugares de memória. Museologia e Patrimônio. Pelotas, v II, n. 1, p.1-14, 2009. Disponível em: https://goo.gl/bsTazP. Acesso em: 20 ago. 16.

FORTUNATO, Eliete Matias. Capital do carvão: identidade em conflito. 2008. $43 \mathrm{f}$. Monografia (Especialização) - Curso de Geografia, Universidade do Estremo Sul Catarinense - Unesc, Cricuma, 2008. Disponível em: https://goo.gl/NQsjYV. Acesso em: 23 set. 2016.

LUDKE, M.; ANDRÉ, M.E.D.A. Pesquisa em educação: abordagem qualitativa. São Paulo, EPU, 1986.

MOGARRO, Maria João. Património educativo e modelos de cultura escolar na história da educação em Portugal. Cuestiones Pedagógicas, Lisboa, p.67-101, 2013. Disponível em: https://goo.gl/3qUQC3 . Acesso em: 07 out. 2016.

MOGARRO, Maria João. Arquivos e educação: a construção da memória educativa. Revista Brasileira de História da Educação, Lisboa, p.77-99, 2005. Disponível em: https://goo.gl/p5Z1sP. Acesso em: 07 out. 2016.

OLIVEIRA, Maria Augusta Martiarena; LANGE, Giana. O Culto aos patronos: As fotografias de inauguração de retratos em um grupo escolar. História, Imagem e Narrativas, Rio Grande do Sul, p.1-12, out. 2009. Disponível em: https://goo.gl/7ujNT6. Acesso em: 30 ago. 16.

PAOLI, Maria Célia. Memória, história e cidadania: o direito ao passado. In. O direito à memória: patrimônio histórico e cidadania. São Paulo: DPH, 1992, p. 25-28. Disponível em: https://goo.gl/fg2wWi. Acesso em: 10 out. 2016.

RABELO, Giani. Entre o hábito e o carvão: pedagogia missionárias no sul de santa catarina na segunda metade do século XX. 2007. 415 f. Tese (Doutorado) - Curso de Educação, Universidade Federal do Rio Grande do Sul, Santa Catarina, 2007.

SILVA, Luis Carlos Borges da. A importância do estudo de história regional e local na educação básica. In: XXVII simpósio nacional de história, 2013, Natal: Anpuh, 2013. p. 1 - 11. Disponível em: https://goo.gl/JbXoG3. Acesso em: 07 ago. 2016.

SOUZA, Rosa Fátima de. Preservação do Patrimônio Histórico Escolar no Brasil: notas para um debate. Revista Linhas, Florianópolis, v. 14, n. 26, jan./jun. 2013. p. 199 221. Disponível em: https://goo.gl/h0ZJ7Y. Acesso em 30 de ago. 16.

SOUZA, Rosa Fátima. Templos de Civilização: a implantação da escola primária graduada no estado de São Paulo: (1890-1910). São Paulo: UNESP, 1998. 302 p

TRIBUNA CRICIUMENSE. Duas mil casas para mineiros. Criciúma, 12 ago. 1957.

Saberes Pedagógicos, Criciúma, v. 1, n², julho/dezembro 2017.- Curso de Pedagogia- UNESC 
VON SIMSON, Olga Rodrigues de Moraes. Memoria, cultura e poder na sociedade do esquecimento: o exemplo do centro de memória da UNICAMP. In: FARIA FILHO, Luciano Mendes de (Org.). Arquivos, fontes e novas tecnologias: questões para a história da educação. São Paulo: Autores Associados, 2000. Cap. 5, p. 63-74.

ZANCUL, Maria Cristina de Senzi. Patrimônio educativo e patrimônio históricocientífico no Brasil: alguns apontamentos. Museologia e Patrimônio, São Paulo, v. 8, n. 2, p.104-122, 2015. Disponível em: https://goo.gl/KhWUpY. Acesso em: 16 out. 2016. 